\title{
The Meanings of Salutogenesis
}

\author{
Maurice B. Mittelmark and Georg F. Bauer
}

\section{Introduction}

In the health promotion field, the term salutogenesis is associated with a variety of meanings that Aaron Antonovsky introduced in his 1979 book Health, Stress and Coping and expounded in many subsequent works. In its most thoroughly explicated meaning, salutogenesis refers to a model described in detail in Antonovsky's 1979 Health, Stress and Coping, which posits that life experiences help shape one's sense of coherence-the sense of coherence. A strong sense of coherence helps one mobilise resources to cope with stressors and manage tension successfully. Through this mechanism, the sense of coherence helps determine one's movement on the health Ease/Dis-ease continuum.

In its narrower meaning, salutogenesis is often equated with one part of the model, the sense of coherence, defined as:

... a global orientation that expresses the extent to which one has a pervasive, enduring though dynamic feeling of confidence that one's internal and external environments are predictable and that there is a high probability that things will work out as well as can reasonably be expected. (Antonovsky, 1979, p. 123).

In its most general meaning, salutogenesis refers to a scholarly orientation focusing attention on the study of the origins of health and assets for health, contra the origins of disease and risk factors.

These meanings are distinct, yet inextricably intertwined, and this may cause confusion: the heart of the salutogenic model is the sense of coherence, a global 'orientation' easily

\section{M.B. Mittelmark ( $₫)$}

Department of Health Promotion and Development, Faculty of Psychology, University of Bergen, Bergen, Norway e-mail: maurice.mittelmark@uib.no

\section{G.F. Bauer}

Division of Public and Organizational Health, Epidemiology, Biostatistics and Prevention Institute, University of Zürich, Zürich, Switzerland

e-mail: georg.bauer@uzh.ch conflated with the salutogenic 'orientation', since the concept of orientation is central to both. A helpful distinction is that orientation in relation to the sense of coherence has relevance for an individual's ability to engage resources to cope with stressors, while orientation in relation to salutogenesis refers to scholars' interest in the study of the origins of health and assets for health rather that the origins of disease and risk factors.

This book is about salutogenesis in all these meaningsthe model, the sense of coherence and the orientation. These meanings are taken up in this chapter to set the stage for the chapters that follow. We also briefly discuss salutogenesis in relation to other concepts within and beyond the health arena, with which salutogenesis has important kinship.

\section{The Salutogenic Model}

By his own account, the turn in Antonovsky's life from pathogenesis to salutogenesis began to crystallise in the late 1960s. Having worked up to that point as a stress and coping survey researcher with foci on multiple sclerosis, cancer and cardiovascular diseases, he came to realise that his real interest did not have its starting point in any particular disease. The starting point, rather, was "the illness consequences of psychosocial factors howsoever these consequences might be expressed" (Antonovsky, 1990, p. 75). This insight led to research and publications on the ideas of 'ease/dis-ease' (breakdown) and generalised resistance resources, but it did not mark the full emergence of salutogenesis in his thinking. At this stage of his career, Antonovsky's focus was still pathogenic (ibid, p. 76). Another decade would pass before Antonovsky came to the question 'what makes people healthy?' and the need to coin the term salutogenesis to convey the mode of thinking implied by the question. The time and space to develop these ideas came while he was on sabbatical at Berkeley in 1977 and 1978. 
The fruition was Antonovsky's full exposition of salutogenesis in Health, Stress and Coping (Antonovsky, 1979), the publication of which completed his turn from pathogenesis to salutogenesis. Antonovsky's illustration of the salutogenic model is reproduced in Fig. 2.1, and the salutogenic model is discussed in detail in Chap. 4. Up to the point of the 1979 book, no research based on the salutogenic model had yet been undertaken. The model's core construct, the sense of coherence, had yet to be fully developed, operationalized and measured, and it was to this task that Antonovsky turned his effort. The result, his book Unraveling the Mystery of Health (Antonovsky, 1987), focused a great deal of his attention on the sense of coherence and its role as an independent variable in health research (Eriksson and Lindström, 2006; Eriksson and Lindström, 2007). Other aspects of the salutogenic model received less attention, and Antonovsky's own ambitions for further development of the salutogenic model were cut short by his death at age 71 , just 7 years following the publication of Unraveling the Mystery of Health.

The literature devoted to the salutogenic model is unsurprisingly modest; salutogenesis, born of a sociologist/ anthropologist only in 1979 , is still is a social science idea in infancy. Mainstream health professions and disciplines have yet to be strongly touched by salutogenesis, even if Antonovsky was professionally situated in a medical school during all the years he developed salutogenesis. The venerated Dorland's Illustrated Medical Dictionary, in print since 1900 and now in its 32nd Edition, does not even have an entry for salutogenesis, much less the salutogenic model (Dorland, 2011).

The salutogenic model has not yet deeply penetrated social science or medicine. That does not mean there is no penetration, and the chapters of this book are evidence that certain health-related arenas are captivated. Yet many scholars who do refer to the salutogenic model stray far from its main ideas. Interest in the model's details is watered down by the sweeping generality of the salutogenic orientation, and by the intense interest the sense of coherence awakens. Four aspects of the salutogenic model that require attention are mostly neglected (a) the origins of the sense of coherence, (b) other answers to the salutogenic question than the sense of coherence, (c) health defined as something other than the absence of disease and (d) processes linking the sense of coherence and health.

Starting with the origins of the sense of coherence, it develops, according to the salutogenic model, from infancy and the infant's experience of its sociocultural and historic context. Antonovsky wrote extensively about the roles of culture in salutogenesis and the development of the sense of coherence (Benz, et al, 2014). His writings included attention to the role of culture in shaping life situations, in giving rise to stressors and resources, in contributing to life experiences of predictability, in load balance and meaningful roles, in facilitating the development of the sense of coherence and in shaping perceptions of health and well-being (ibid). Yet, with almost the sole exception of work by Israelis, culture is not a theme in salutogenesis research (see as examples Braun-Lewensohn and Sagy, 2011; Sagy, 2015). One might protest and point to the plethora of studies in which translations of sense of coherence questionnaires have been developed, but such research is not the study of the cultural forces that Antonovsky called attention to.

Stepping up the ladder of the salutogenic model, cultural and historical context is understood as a cauldron generating psychosocial stressors and resistance resources. It is the life experience of bringing resources to bear on coping with stressors that shapes the sense of coherence. Yet the processes involved are little studied. Which psychosocial resources are predictably generated by which child rearing patterns, which social role complexes and the interaction of these? Is it the case that generalised resistance resources are of prime importance to the development of the sense of coherence as Antonovsky maintained, or do specialised resistance resources (SRRs) also play a vital role (see Chap. 9 for more on this issue)? How does the experience of stress affect the shaping of resistance resources? Unaddressed questions about the origins of the sense of coherence abound.

Moving on to the issue of other answers to the salutogenic question than the sense of coherence, Antonovsky invited others to search for them, even if his interest remained firmly with the sense of coherence. The question is this: what factors (presumably besides the sense of coherence) intervene between the stress/resources complex on the one hand and the experience of health on the other hand? A convenient way to partition the question is with the intra-person/extra-person differentiation. The sense of coherence is an intra-person factor; which other intraperson factors may be at play? There are many candidates (hardiness, mastery and so forth), but little effort to compare and contrast their mediating and moderating roles with the sense of coherence in the same research designs.

As to extra-person salutary factors, there is at least movement in promising directions. In the work and health literature specifically, and in the settings literature more generally, interest is growing in how physical and social environments can be managed to enhance well-being and performance (see Parts V and VI). Such research is attentive to the sociocultural environment, not as an early force in the shaping of the sense of coherence, but as a mediating factor which may facilitate coping. In the health promotion area, this is referred to as 'supportive environments' and a fundamental precept is that healthy policy should create supportive environments. An example of a salutary extra-person factor is work-family corporate support policy, which is a 

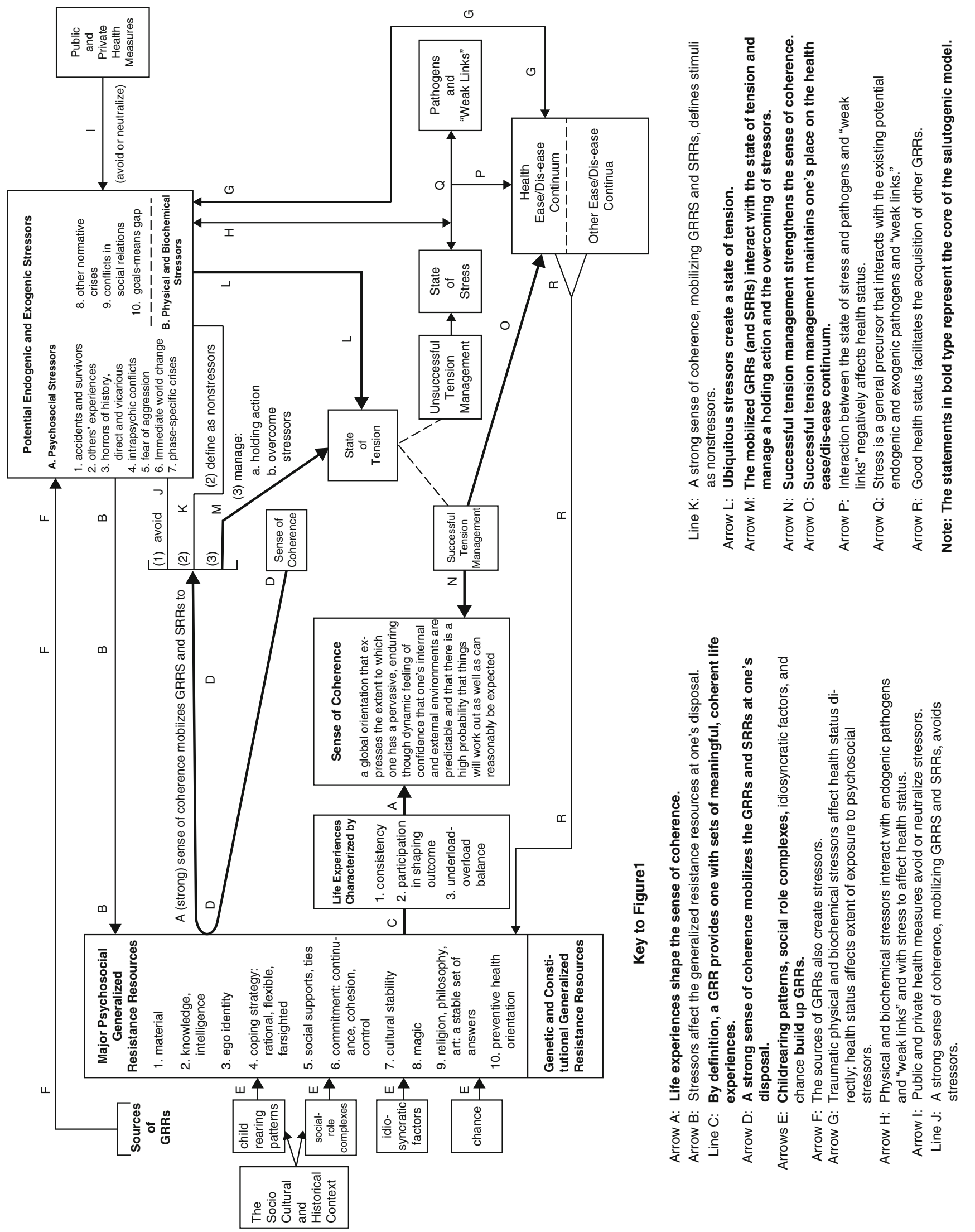
SRR related positively to job satisfaction, job commitment and intentions to stay on the job (Butts, Casper, and Yang, 2013). Most interestingly, it may be that the perceived availability of support under such policy, rather than actual use of supports, is the critical factor in good job-related outcomes (ibid).

Moving to health defined as something other than the absence of disease, the definitions of health evident in the salutogenesis literature are not as specified in the salutogenic model (Mittelmark and Bull, 2013). This is not a point of critique, since there are good reasons why this is so (ibid). Rather, it is a comment on the casual treatment the salutogenic model receives. Research articles reporting on the relationship of the sense of coherence to a wide range of disease endpoints fail to note that this is a drastic departure from the specifications of the salutogenic model; the discrepancy is not just ignored, it is unnoticed.

Finally, moving to the issue of processes linking the sense of coherence and health, the salutogenic model posits that the sense of coherence helps a person mobilise generalised resistance resources and specific resistance resources in the face of psychosocial and physical stressors; this may end with stressors (1) avoided, (2) defined as non-stressors, (3) managed/overcome, (4) leading to tension that is subsequently managed with success (and enhancing the sense of coherence) or (5) leading to unsuccessfully managed tension. These outcomes have impact on one's movement on the Ease/Dis-ease continuum, but what mechanisms link the sense of coherence and movement on the continuum? The sense of coherence is postulated as an orientation (in the sense of attitude, predisposition or proclivity), not a cognitive and/or emotional mechanism that converts information about stressors and resources into coping responses. What else happens in the brain that lies between the sense of coherence and coping responses? This is a little studied question, surprising since the brain plays a huge role in the salutogenic model. Chapters 6 and 29 address this question (a psychological process called 'self-tuning' is described), but the search for factors that intervene the sense of coherence and stress/resources/coping experience remains a rarity.

The discussion above suggests neglected development of the salutogenic model. Why is the model relatively neglected? One obvious answer is its newness; another is that Antonovsky himself did not pursue empirical testing of the whole, very complex model. Instead, he focused on the sense of coherence, which he considered as the key concept, and even as the ultimate dependent variable in salutogenic thinking. Thus, it is not surprising that many other scholars have followed his inspiring lead and focused on the study of the sense of coherence part of the model.

\section{Salutogenesis as the Sense of Coherence}

Salutogenesis was situated by Antonovsky as a question: what are the origins of health? His answer was the sense of coherence. The question and this answer comprised the heart of his salutogenic model as just discussed. Antonovsky invited other answers to the salutogenic question, while remaining convinced that his own answer was fundamental. The way Antonovsky posed and answered the question of salutogenesis was challenging. While 'origins' - he used the plural form-signals the possibility of multiple healthgenerating determinants and processes, his singular answer - the sense of coherence — suggested a channelling of all salutogenic processes through a particular mental orientation. This singular answer provides an appealing reduction of complexity compared to the concept of pathogenesis, with its legion of risk factors:

\footnotetext{
"A salutogenic orientation, I wrote, provides the basis, the springboard, for the development of a theory which can be exploited by the field of health promotion [...] which brings us to the sense of coherence" (Antonovsky, 1996).
}

He considered the sense of coherence as the key concept of the salutogenic model. We say no more about the content of the sense of coherence idea here, referring the reader instead to Part III of this book, which is devoted to the topic. Rather, we focus on the question, why has this single-minded answer-the sense of coherence-been overriding as the answer to the salutogenic question? Why is the sense of coherence actually equivalent in meaning to salutogenesis, for so many scholars?

Firstly, Antonovsky strongly signalled that of all the aspects of the salutogenic model, the sense of coherence deserved singular attention. In his very influential 1996 paper in Global Health Promotion, Antonovsky proposed a research agenda consisting solely of sense of coherence questions:

- "Does the sense of coherence act primarily as a buffer, being particularly important for those at higher stressor levels, or is it of importance straight down the line?

- Is there a linear relationship between sense of coherence and health, or is having a particularly weak (or a particularly strong) sense of coherence what matters?

- Does the significance of the sense of coherence vary with age, e.g., by the time the ranks have been thinned, and those who survive generally have a relatively strong sense of coherence, does it still matter much?

- Is there a stronger and more direct relationship between the sense of coherence and emotional wellbeing than with physical wellbeing? 
- What is the relationship between the movement of the person toward wellbeing and the strength of his/her collective sense of coherence?

- Does the sense of coherence work through attitude and behavior change, the emotional level, or perhaps, as suggested by the fascinating new field of PNI (psychoneuroimmunology), from central nervous system to natural killer cells?" (Antonovsky, 1996, pp. 16, 17).

Importantly, some of these questions focus on neglected issues as discussed in the paragraphs above on the salutogenic model. Yet Antonovsky's focus on the sense of coherence was crystal clear, and that undoubtedly influences the choices of subsequent generations of salutogenesis researchers.

Besides the importance of Antonovsky's lead, the sense of coherence has the charm of relative simplicity: it suggests that all salutogenic processes are channelled through a measurable global life orientation. Thus, this single, focused concept greatly reduces complexity. Further, the sense of coherence concept has high face validity for both researchers and populations it is applied to, as it makes immediate sense that perceiving life as comprehensible, manageable and meaningful is conducive to health. Also, it is supposedly more complete and generalisable, and not culture-bound, in contrast to concepts such as internal locus of control and mastery. The combination of cognitive, behavioural and motivational components positions the sense of coherence uniquely... and they are all measureable.

This last point, that the sense of coherence is appealingly measurable, may be the most significant reason for its centre stage position in the salutogenesis literature. In the prestigious journal Social Science and Medicine, Antonovsky (1993) published a paper titled The Structure and Properties of the Sense of Coherence Scale, cited as of this writing by over 2500 publications, a momentous achievement. Within just a few years, Antonovsky's sense of coherence scale had been used in "at least 33 languages in 32 countries with at least 15 different versions of the questionnaire" (Eriksson and Lindström, 2005). The stream of sense of coherence measurement papers has continued unabated (Rajesh et al., 2015).

Thus, it is understandable that for many, salutogenesis is synonymous with the sense of coherence: it is Antonovsky's answer to the salutogenic question, it was his sole priority for further research, and sense of coherence measurement has scientific importance... and panache.

\section{The Salutogenic Orientation}

In his last paper, published posthumously, Antonovsky (1996) wrote:

"I was led to propose the conceptual neologism of salutogenesis - the origins of health-(Antonovsky, 1979). I urged that this orientation would prove to be more powerful a guide for research and practice than the pathogenic orientation."

Was Antonovsky predicting a paradigm shift? It is important to note that the 1996 paper cited above was directed at the field of health promotion, which Antonovsky felt had too whole-heartedly accepted pathogenesis thinking and disease prevention via risk factor reduction. Expressing his hopes for 'proponents of health promotion', Antonovsky wrote that the salutogenic orientation might help them "carve out an autonomous existence - though one undoubtedly in partnership with curative and preventive medicine" (Antonovsky, 1996). Not so much a complete paradigm shift from pathogenesis to salutogenesis, Antonovsky wished to foment a shift to salutogenesis as a viable theory basis and as an essential supplement to pathogenesis in the health and social sciences (Mittelmark and Bull, 2013). Yet, in introducing the salutogenic orientation, Antonovsky referred explicitly to Thomas Kuhn's $(1962,2012)$ idea of paradigmatic axioms which need to change for a paradigm shift to emerge. His thoughts were on

\footnotetext{
"the axiom ... which is at the basis of the pathogenic orientation which suffuses all western medical thinking: the human organism is a splendid system, a marvel of mechanical organization, which is now and then attacked by a pathogen and damaged, acutely or chronically or fatally" (Antonovsky, 1996).
}

Challenging this axiom, Antonovsky summarizes the essence of the salutogenic orientation in contrast to the pathogenic orientation (Antonovsky, 1996):

- In contrast to the dichotomous classification of pathogenesis into healthy or not, salutogenesis conceptualizes a healthy/dis-ease continuum

- In contrast to pathogenesis' risk factors, salutogenesis illuminates salutary factors that actively promote health

- In contrast to focusing on a "particular pathology, disability or characteristic" of a person, salutogenesis might work with a community of persons and "must relate to all aspects of the person"

We return to our earlier question, slightly rephrased: was Antonovsky calling for a paradigm shift from pathogenesis to salutogenesis? Certainly not in the sense of salutogenesis as the usurper of pathogenesis; he remarked repeatedly that pathogenesis would remain dominate in the 'health' arena. But he did hope that salutogenesis would achieve an ascendant position as the theory of health promotion. This is not yet achieved, but salutogenesis is on the rise. The Health Development Model (Bauer, et al., 2006, see Fig. 6.1 in Chap. 6) is a prominent framework for the development of health promotion indicators, and it explicitly incorporates aspects of both pathogenesis and salutogenesis. If the concept of paradigm shift is not too grand to apply, we could say that the shift is to a paradigm that incorporates pathogenesis 
and salutogenesis. This shift, even if modest so far, is perhaps the most promising contribution of the salutogenic orientation to the health and social sciences. Compared to other concepts relevant to a search for the origins of health, such as assets, resources, coping and resilience, salutogenesis is in a sense a more complete concept, offering a new outlook on health outcomes, health determinants and health development processes. For many health promotion researchers, using the term 'salutogenesis' communicates at a minimum that one pursues an alternative approach to pathogenesis.

This inclusive sense of salutogenesis is captured by Lindström and Eriksson's umbrella image, which effectively communicates that many health resources and assets concepts (e.g. social support, the sense of coherence, selfefficacy, hardiness and action competency) have kinship under the salutogenesis umbrella (Eriksson and Lindström, 2010). The umbrella also covers diverse positive health conceptions such as quality of life, flourishing and wellbeing. Seen in this light, salutogenesis might be defined simply as processes wherein people's and communities' resources are engaged to further individual and collective health and well-being. Of course, this umbrella concept is a particular view of the salutogenesis aficionado; a selfefficacy researcher might be inclined to place salutogenesis under the umbrella in the company of all the other positive health concepts.

\section{Salutogenesis in Context: Comparable Concepts and Developments}

The salutogenic model originated as a stress and coping model (Antonovsky, 1979). Antonovsky referred to Selye's (1956) and Lazarus and Cohen's (1977) work as particularly inspirational. As does the salutogenic model, Lazarus and Cohen's transactional model of stress assumes an interaction between external stressors and a person who evaluates stressors based on the resources available to cope. In the domain of working life, the well-established job DemandControl Model (Karasek, 1979; Bakker, van Veldhoven, \& Xanthopoulou 2015), the Effort Reward Imbalance Model (Siegrist, Siegrist, and Weber 1986; Van Vegchel et al., 2005) and the more generic Job Demands-Resources Model (Bakker \& Demerouti, 2007) share with the salutogenic model the basic idea of a balance between stressors and resources-and that they have been mainly empirically tested in relation to disease outcomes. In a recent development, an organisational health model has emerged from the explicit linking of elements of the Job DemandResource Model (Bakker and Demerouti, 2007) with salutogenesis (Bauer and Jenny, 2012, Brauchli, Jenny, Füllemann, \& Bauer 2015).
Salutogenesis as an orientation is an idea in close concert with a broad academic movement towards a positive perspective on human life. There are traces of salutogenesis in philosophy at least since Aristotle reflected about the hedonic and eudaimonic qualities of (positive) health (Ryan \& Deci, 2001). Three decades before Health, Stress and Coping, the Constitution of the World Health Organization exclaimed that "health is more than the absence of disease". Illich (1976) critiqued the medicalisation of life. Social epidemiology has a long tradition of considering broad social determinants of health beyond the proximal disease risk factors (Berkman, Kawachi, \& Glymour 2014). More recent parallel developments include research on positive organisational behaviour in organisational psychology (Nelson \& Cooper), on happiness in management research (Judge \& Kammeyer-Mueller 2011), on place as a resource in social ecology (Von Lindern, Lymeus \& Hartig, this volume), on promoting strengths in educational sciences (Jensen, Dür \& Buijs this volume) and on pre-conditions for substantially rewarding, satisfying and fulfilling lives in sociology (Stebbins, 2009; Thin, 2014). Chapter 11 in this book on positive psychology describes vibrant developments in the emerging positive health paradigm. In the field of health promotion, the positive paradigm may be seen in recent literature of two kinds: that which describes protective factors against untoward outcomes (e.g. Boehm and Kubzansky, 2012) and that which describes factors that promote well-being (Eriksson and Lindström, 2014).

\section{Conclusions}

This chapter-and this Handbook-introduce a broad swath of developments that excite the present generation of salutogenesis scholars. Some of these developments are clearly relevant to the salutogenic model, others are firmly focused on the sense of coherence, and yet others are more identifiable with salutogenesis as an orientation. The book also takes up parallel developments in the areas of positive psychology, occupational and organizational health sciences, social ecology and educational sciences which may make little explicit reference to salutogenesis, and yet are in evident close kinship with salutogenesis. It is one of the main aims of this book to invite an inclusive, bridging dialogue, meant to nourish salutogenesis... in all its meanings. The book also aims to introduce salutogenesis researchers to scientific kinfolk who contemplate matters highly relevant to salutogenesis, even if they do so in literatures not searchable with the key word 'salutogenesis'. 
Open Access This chapter is distributed under the terms of the Creative Commons Attribution-Noncommercial 2.5 License (http:// creativecommons.org/licenses/by-nc/2.5/) which permits any noncommercial use, distribution, and reproduction in any medium, provided the original author(s) and source are credited.

The images or other third party material in this chapter are included in the work's Creative Commons license, unless indicated otherwise in the credit line; if such material is not included in the work's Creative Commons license and the respective action is not permitted by statutory regulation, users will need to obtain permission from the license holder to duplicate, adapt or reproduce the material.

\section{References}

Antonovsky, A. (1979). Health, stress and coping. San Francisco, CA: Jossey-Bass.

Antonovsky, A. (1987). Unraveling the mystery of health-How people manage stress and stay well. San Francisco, CA: Jossey-Bass.

Antonovsky, A. (1990). A somewhat personal odyssey in studying the stress process. Stress Medicine, 6(2), 71-80.

Antonovsky, A. (1993). The structure and properties of the sense of coherence scale. Social Science and Medicine, 36(6), 725-733.

Antonovsky, A. (1996). The salutogenic model as a theory to guide health promotion. Health Promotion International, 11, 11-18.

Benz, C., Bull, T., Mittelmark, M., \& Vaandrager, L. (2014). Culture in salutogenesis: the scholarship of Aaron Antonovsky. Global Health Promotion, 21(4), 16-23. doi:10.1177/1757975914528550.

Dorland, W. A. N. (2011). Dorland's illustrated medical dictionary32: Dorland's illustrated medical dictionary. Philadelphia, PA: Elsevier Health Sciences.

Bakker, A. B., \& Demerouti, E. (2007). The job demands-resources model: state of the art. Journal of Managerial Psychology, 22, 309-328.

Bakker, A. B., van Veldhoven, M., \& Xanthopoulou, D. (2015). Beyond the demand-control model. Journal of Personnel Psychology, 9(1), 3-16.

Bauer, G., Davies, K. D., \& Pelikan, J. (2006). The EUPHID health development model for the classification of public health indicators. Health Promotion International, 21, 153-159.

Bauer, G. F., \& Jenny, G. J. (2012). Moving towards positive organisational health: Challenges and a proposal for a research model of organisational health development. In J. Houdmondt, S. Leka, \& R. R. Sinclair (Eds.), Contemporary occupational health psychology: Global perspectives on research and practice (Vol. 2). Oxford: Wiley-Blackwell.

Berkman, L. F., Kawachi, I., \& Glymour, M. (Eds.). (2014). Social epidemiology. Oxford: Oxford University Press.

Boehm, J. K., \& Kubzansky, L. D. (2012). The heart's content: the association between positive psychological well-being and cardiovascular health. Psychological Bulletin, 138(4), 655.

Brauchli, R., Jenny, G. J., Füllemann, D., \& Bauer, G. F. (2015). Towards a job demands-resources health model: Empirical testing with generalizable indicators of job demands, job resources, and comprehensive health outcomes. BioMed Research International, $2015,959621$.

Braun-Lewensohn, O., \& Sagy, S. (2011). Salutogenesis and culture: Personal and community sense of coherence among adolescents belonging to three different cultural groups. International Review of Psychiatry, 23(6), 533-541.
Butts, M. M., Casper, W. J., \& Yang, T. S. (2013). How important are work-family support policies? A meta-analytic investigation of their effects on employee outcomes. Journal of Applied Psychology, 98(1), 1.

Eriksson, M., \& Lindström, B. (2005). Validity of Antonovsky's sense of coherence scale: A systematic review. Journal of Epidemiology and Community Health, 59(6), 460-466.

Eriksson, M., \& Lindström, B. (2006). Antonovsky's sense of coherence scale and the relation with health: a systematic review. Journal of Epidemiology and Community Health, 60(5), 376-381.

Eriksson, M., \& Lindström, B. (2007). Antonovsky's sense of coherence scale and its relation with quality of life: A systematic review. Journal of Epidemiology and Community Health, 61 (11), 938-944.

Eriksson, M., \& Lindström, B. (2010). Bringing it all together: The salutogenic response to some of the most pertinent public health dilemmas. In A. Morgan, E. Ziglio, \& M. Davies (Eds.), Health assets in a global context: Theory, methods, action (pp. 339-351). New York: Springer.

Eriksson, M., \& Lindström, B. (2014). The salutogenic framework for well-being: Implications for public policy. In T. J. Hämäläinen \& J. J. Michaelson (Eds.), Well-being and beyond: Broadening the public and policy discourse: New horizons in management (pp. 68-97). Northampton, MA: Edward Elgar.

Illich, I. (1976). Medical nemesis: The expropriation of health. New York: Pantheon Books.

Judge, T. A., \& Kammeyer-Mueller, J. D. (2011). Happiness as a societal value. Academy of Management Perspectives, 25, 30-41.

Karasek, R. A. (1979). Job demands, job decision latitude, and mental strain: Implications for job redesign. Administrative Science Quarterly, 24, 285-308.

Kuhn, T. S. (1962). The structure of scientific revolutions. Chicago, IL: The University of Chicago Press.

Lazarus, R. S., \& Cohen, J. B. (1977). Environmental stress. In I. Altman \& J. F. Wohlwill (Eds.), Human behavior and environment (Vol. 2). New York: Plenum.

Mittelmark, M. B., \& Bull, T. (2013). The salutogenic model of health in health promotion research. Global Health Promotion, 20(2), 30-38.

Nelson, D., \& Cooper, C. L. (2007). Positive organizational behavior. Thousand Oaks, CA: Sage.

Rajesh, G., Eriksson, M., Pai, K., Seemanthini, S., Naik, D. G., \& Rao, A. (2015). The validity and reliability of the sense of coherence scale among Indian university students. Global Health Promotion. doi:10.1177/1757975915572691.

Ryan, R. M., \& Deci, E. L. (2001). On happiness and human potentials: A review of research on hedonic and eudaimonic well-being. Annual Review of Psychology, 52(1), 141-166.

Sagy, S. (2015). Coping, conflict and culture: The salutogenic approach in the study of resiliency. In D. Ajdukovic, S. Kimhi, \& M. Lahad (Eds.), Resiliency: Enhancing coping with crisis and terrorism (pp. 41-48). Clifton, NJ: Ios Press.

Selye, H. (1956). The stress of life. New York: McGraw-Hill.

Siegrist, J., Siegrist, K., \& Weber, I. (1986). Sociological concepts in the etiology of chronic disease: the case of ischemic heart disease. Social Science \& Medicine, 22, 247-253.

Stebbins, R. A. (2009). Personal decisions in the public square: Beyond problem solving into a positive sociology. New Brunswick, NJ: Transaction.

Thin, N. (2014). Positive sociology and appreciative empathy: History and prospects. Sociological Research Online, 19(2), 5.

Van Vegchel, N., De Jonge, J., Bosma, H., \& Schaufeli, W. (2005). Reviewing the effort-reward imbalance model: Drawing up the balance of 45 empirical studies. Social Science \& Medicine, 60(5), $1117-1131$. 